\title{
COM TATO EM TELA: afetos e artefatos maquínicos
}

\author{
Patrícia Rocha ${ }^{1}$
}

Resumo: O presente artigo busca refletir sobre as relações afetivas mediadas pela tecnologia na contemporaneidade. Em um período ditado pela sobreposição de códigos de relacionamentos produzidos durante o processo de mediação tecnológica, o mapa signico para o rastreamento das manifestações ditas de afeto provavelmente advenha da chamada força bruta indicial da emoção presentificada nessas comunicações.

Palavras-chave: Afeto, tecnologia, artefatos, redes, mediação, subjetivação, percepção, presentificação da experiência.

\begin{abstract}
This article aims to reflect on the affective relations mediated by technology in the contemporary world. In a period dictated by the overlapping of codes of relationships produced during the process of technological mediation, the signal map for the tracing of affection manifestations derives from indicial gross force of the presentificated emotion in these communications.
\end{abstract}

Keywords: Affection, technology, artefacts, webs, mediation, subjectivation, perception, experience presentification.

\section{Introdução}

Que relação haveria entre as tentativas de estabelecimento de contato (comunicação ou interação em níveis avançados) com inteligências extraterrestres apresentados em filmes de ficção científica e as interações de relações afetivas mediadas por tecnologia na contemporaneidade? Talvez para alguns essa pergunta soe exagerada e dramática. Embora ainda não vejamos espaçonaves em formas de disco cruzando os céus com naturalidade como foi imaginada em séries e desenhos animados, o século XXI apresenta traços que nos aproxima assustadoramente da realidade sugerida em criativos roteiros de cinema de ficção.

O presente artigo busca fazer um paralelo entre os recursos de interatividade entre humanos e alienígenas - como os sinais audiovisuais de satélite, intervenções sonoras e luminosas - que aparecem nos filmes "Contato" (1997) e "Contato Imediatos do Terceiro Grau" (1977) e as relações afetivas mediadas por tecnologias de rede na contemporaneidade. A individualização excessiva teria transformado as formas de sociabilidade e as percepções de relacionamento afetivo de maneira que o acesso ao outro indivíduo tenha se tornado um desafio misterioso ou até mesmo um grande perigo - isso, apesar de toda a aparente segurança

\footnotetext{
${ }^{1}$ Mestre em Comunicação Social pela PUC Minas, professora e artista. Já lecionou para os cursos de Publicidade e Jornalismo da PUC Minas e para o programa de ensino técnico nacional PRONATEC no COLTEC-MG.
} 
que a malha de filtros e informações sobre os usuários servidos pela rede venha a oferecer. Os dados disponíveis sobre gostos e preferências pessoais funcionariam, em tese, como uma aparente apólice de seguros, uma vez antecipariam possíveis surpresas que poderiam acontecer no enfrentamento de um encontro presencial. Contudo, as imagens, vídeos, preferências musicais de um perfil virtual não constituiriam um mosaico interpretativo com exclusivo fim de atrair a atenção do outro usuário, sem necessário compromisso com a verdade? Como se conformaria a sensação de segurança neste tipo de interação e mediação?

\section{Contatos em telas}

O filmes "Contato" (1997) e "Contato Imediato do Terceiro Grau" (1997) utilizam o som ou a música como interface primeira de comunicação entre as inteligências extraterrestres e a humanidade. Por trás da música enquanto código estaria a matemática como uma espécie de linguagem universal do espaço e da existência.

No filme "Contato" (1997), a primeira percepção da existência de uma iniciativa de comunicação foi a frequência sonora captada pela cientista responsável pelo projeto SETI (antenas direcionadas para as galáxias em busca de sinais de rádio que representem um contato alienígena). No decorrer do processo de comunicação acontece a decodificação da onda em sinais matemáticos, números primos, que não seriam produzidos espontaneamente no universo. Neste mesmo processo de decodificação surgiu uma imagem da segunda guerra mundial que seria uma espécie de resposta a uma iniciativa da agência espacial americana, que teria mandado um disco de imagens do Planeta Terra em direção ao espaço sideral. Aquilo poderia significar duas coisas, um chamado de paz ou um chamado de luta.

No filme "Contatos Imediatos do Terceiro Grau" (1977), a manifestação foi inicialmente "material", uma vez as testemunhas interagiram visualmente com as naves alienígenas. Elas foram expostas a experiências de forte impacto emocional de maneira que informações foram inseridas em suas mentes sem que elas soubessem, reaparecendo depois em suas memórias paulatinamente. Essas memórias forneceram a imagem do local onde aconteceria um novo contato direto e mais elaborado. Nesse segundo momento, por exemplo, as notas musicais eram repetidas numa sequência fixa que, ao acelerar-se complexificava ou sinalizava o avanço do nível de interação. 
A música ou o som como interface de mediação produz uma "pré-sensação" de familiaridade, as notas musicais e escalas, que nos tocam de modo a parecer que converse diretamente com as nossas emoções. O som nesse momento tem uma característica indicial, está no lugar da Segundeza nas categorias de fenômenos de percepção de Peirce. O som chega causando uma identificação, uma afinidade ou repulsa, uma reação:

Segundeza está nos domínios daquilo que chamamos de atual (=ato), de presencial, do visto, do sentido conscientemente, daquilo que percebemos sabendo dessa percepção. A Segundeza é algo do mundo que se impõe à nossa consciência, que se faz perceber de forma bruta por simplesmente estar lá, por se fazer presente. Isto é, a Segundeza é a categoria daquilo que sentimos existir. (PINTO, p.45, 2010)

Quando os contatos estabelecidos pelas inteligências alienígenas se "materializam" na Segundeza eles estão se colocando para a cognição humana como uma espécie de verdade, de confirmação da experiência e vivência.

Em nossas relações mediadas tecnologicamente, buscamos nos dispositivos formas e materialidades para as nossas interações e relações. A partir do momento em que elas são canalizadas em um dispositivo eletrônico de "curadoria" de relação e de estímulo visual, estaríamos buscando de alguma forma uma certeza para o investimento naquela relação ou a ilusão de vivência dessa afetividade?

[...] a experiência reticular dos ambientes digitais constitui uma propulsão no sentido da singularização das experiências, isto é, uma manifestação do sensível em sua proximidade com os absolutos irredutíveis de uma zeroidade que não se alcança. Essa singularização oferece o tato, mais que a idéia do tato, o cheiro, mais que a idéia do cheiro, o tempo presente que sinto na carne, mais que uma idéia de tempo presente. Não é, aliás, o tempo presente que todos compartilhamos, é o meu tempo presente. (PINTO, p.8, 2010)

A vida presentificada das redes sociais talvez cause a sensação de que estejamos vivos e/ou experienciando múltiplas vivências, mas não necessariamente acessando de fato aquilo que alguns objetivam buscar, que seria os afetos mais profundos. Seria o amor um sentimento indizível, situado na Primeireza (qualidade difusamente percebida de minha experiência) numa condição mais próxima de uma "zeroidade" ao invés da sensação de realização da Segundeza? Um terceiro (simbólico) funcionado como primeiro? Seriam as interfaces tecnológicas nossas naves espaciais para experienciar "materialmente" o denominado amor? Como funcionariam as redes sociais mediadas tecnologicamente no estabelecimento dessas relações? O que as evoluções técnicas nos dispositivos e aplicativos teriam a revelar? 


\section{Interfaces de espaço e tempo e redes sociais}

Tanto no filme "Contato" (1997) quanto em "Contatos Imediatos do Terceiro Grau" (1977) é observado o flerte com a física e a teoria da relatividade de Einstein, na qual o tempo e o espaço são variáveis relacionadas e deformáveis pela massa do astro e as forças gravitacionais. Em "Contato" (1997), o flerte aparece no trecho em que a pesquisadora faz a sua viagem espacial super acelerada através dos "buracos de minhoca", hipotéticos túneis de deslocamento no espaço-tempo descritos por Einstein. Em "Contatos Imediatos do Terceiro Grau" (1977), os passageiros humanos da nave alienígena que haviam desaparecido há anos da Terra retornaram ao planeta com a mesma aparência física de quando foram abduzidos. A viagem no espaço-tempo teria preservado a juventude dos viajantes enquanto o tempo na Terra avançou normalmente.

A presença contínua da tecnologia no nosso cotidiano promoveu muitas transformações na nossa percepção de espaço e tempo, por exemplo, embora nem todas as pessoas parem para pensar nessas transformações, apenas as vivenciam. A Internet e os smartphones modificaram a maioria de nossas interações à distância. Já assistimos a duas gerações de tecnologia de rede (web 1.0 - dupla Orkut e MSN - e web 2.0 - Facebook e Whatsapp) nas quais podemos reconhecer modelos diferentes de interatividade. A multiplicidade de informações que podemos obter sobre lugares, pessoas, contextos são como "superpoderes" que outrora só seriam possíveis se realizássemos o sonho da telepatia ou da osmose de conhecimento.

Os meios de comunicação e as tecnologias encurtaram distâncias físicas e o tempo de troca interativa. Aceleraram a vida desestabilizando os modos de experiências vigentes até então. Se a televisão interrompeu a tradição das conversas familiares, se o laptop individualizou o uso do computador da família, os smartphones e suas múltiplos aplicativos de redes sociais reduziram a quase zero a necessidade de longas conversas telefônicas, como podemos constatar em nossas experiências cotidianas.

A popularização das tecnologias digitais introduziu a mobilidade em todos os planos de experiência. Com isso espaços que antes apareciam como referências totais passam a ser percebidos de formas diferenciadas para cada indivíduo em seu histórico de experiências. Almeida e Tracy (2003) citam De Certeau para repensar o espaço, no qual este seria constituído pelo cruzamento móvel de corpos e fragmentos. O chamado ciberespaço se 
configurou como uma ambiência de fluxo contínuo de conteúdo que contribuiu para os fenômenos de desterritorialização, termo que se aplica a objetos ou processos que cada vez mais operam de modo a transcender limites territoriais e identidades específicas:

Trata-se de pensar o tempo e o espaço conjuntamente, e ambos como produtos de inter-relações, pois "uma vez superada a hipótese de que o espaço e o tempo são categorias mutuamente exclusivas, uma vez admitido que o espaço é composto por uma multiplicidade de histórias, percebe-se que nada poderia ser a um só tempo mais ordenado e caótico que o espaço, com todas as suas justaposições inusitadas e efeitos emergentes involuntários. (ALMEIDA \& TRACY, 2003, p.28)

As experiências interativas são continuamente atualizadas por novos formatos tecnológicos que produzem um aprendizado de códigos específicos que afetam as percepções e as disposições para as relações afetivas. As autoras resgatam Marc Augé e o conceito de Hipermodernidade para abordar esse acelerado e mutante processo interacional no qual a contemporaneidade seria marcada por superabundâncias:

[...] a superabundância espacial caracteriza-se pela crise dos sistemas de referências baseados na ideia de totalidade, crise esta produzida pela diminuição das distâncias e pela facilidade de comunicação que dissolvem fronteiras materiais e culturais. A superabundância identitária, estreitamente vinculada aos processos apontados anteriormente, caracteriza-se pela individualização exarcebada das referências, o que tornou múltiplos e flutuantes os mecanismos de identificação tanto individuais quanto coletivos. (ALMEIDA \& TRACY, 2003, p.32)

Agamben (2009) já havia mencionado em seu entendimento do conceito de dispositivo que seriam disparadores de processos de subjetivação e dessubjetivação produzidas pelas relações os quais eles mediam:

[...] as substâncias e os sujeitos, como na velha metafísica, parecem sobrepor-se, mas não completamente. Neste sentido, por exemplo, um mesmo indivíduo, uma mesma substância, pode ser o lugar dos múltiplos processos de subjetivação: o usuário de telefones celulares, o navegador na internet, o escritor de contos, o apaixonado por tango, o não-global etc. Ao ilimitado crescimento dos dispositivos no nosso tempo corresponde uma igualmente disseminada proliferação de processos de subjetivação. AGAMBEN, 2009, p.41)

Podemos pensar nos smartphones, por exemplo, e a relação que este dispositivo tem no cotidiano, como ele insere práticas de comunicação através das interações nas redes sociais, desvinculando referenciais de tempo e espaço, uma vez que trata-se de uma "mídia locativa", criando e articulando múltiplas subjetivações que irão conviver com tantas outras subjetivações oriundas de outros dispositivos que se sobrepõem. 
Visualizamos a evolução das interfaces das principais redes sociais de internet ao longo dos últimos doze anos como um exemplo da diversificação das formas de interação mediada por tecnologia. No início dos anos dois mil, a rede social Orkut juntamente com a interface de bate-papos MSN eram os líderes das interações até aproximadamente 2005, quando outras redes despontaram como MySpace e o Twitter. O Orkut tinha um formato baseado na interação em fóruns de debates, nos quais os conteúdos das interações ficavam armazenados por tema ou assunto e os membros dos fóruns formavam comunidades afins em torno de algum interesse comum. O Twitter ${ }^{2}$ com sua interface de atualizações contínuas em textos de poucos caracteres veio inaugurar a cultura da linha de tempo. Plataforma de comunicação constante, individual (não obrigatoriamente prevê a necessidade de diálogo). Quando o Facebook surgiu sua referência era a interface do Orkut. Porém, logo que foi constatado o sucesso do também rival Twitter, o Facebook absorveu a sua dinâmica de

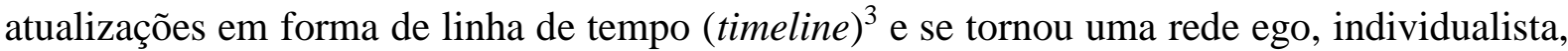
pautada na exibição de uma narrativa que giraria em torno da própria vida transmitida para audiência, retroalimentada por um algoritmo que prioriza os usuários mais atuantes na prática de publicação de postagens.

Diante desse apanhado, fazendo um paralelo sorrateiro com a teoria da equivalência de massa-energia de Einstein, nota-se que o algoritmo de algumas redes sociais proporcionaria uma relação de aceleração e "aumento de massa": quanto maior a frequência de interação, maior a densidade informacional. Mas teria o aumento da interação uma relação direta com o sucesso das trocas afetivas entre estes usuários? Não necessariamente. Porém, certamente, uma repetição da frequência de contato promove algum tipo de padrão interativo que pode se alocar tanto na região do conforto quanto na de conflito, dependerá da profundidade ou intimidade presente no conteúdo trocado.

Partindo dessa constatação, talvez o Orkut com seus fóruns virtuais possa ter gerado relações afetivas mais sólidas que redes sociais como o Facebook e outros aplicativos contemporâneos. Hoje já estamos transitando para uma terceira geração de tecnologia de rede

\footnotetext{
${ }^{2} \mathrm{O}$ Twitter surgiu em 2006, mas sua interface assim como a de outras redes sociais evoluiu a partir das interações dos próprios usuários. Esta informação está disponível em <https://www.tecmundo.com.br/redesocial/3667-a-historia-do-twitter.htm>

${ }^{3}$ A evolução da interface do Facebook pode ser verificada no slideshow "Linha do Tempo: do Facebook ao IPO" da revista Época Negócios disponível em <http:// http://epocanegocios.globo.com/Informacao/Visao/fotos/2012/05/linha-do-tempo-o-facebook-da-criacao-aoipo.html>
} 
social que promova camadas paralelas às redes mais populares, mas não menos bem sucedidas, como é o caso do Tinder.

O Tinder é a interface contemporânea mais famosa para a mediação de relacionamentos ditos "amorosos". A interface também possui características de rede Ego, dando prioridade às fotos e imagem do usuário. Ela possui filtros que já pré-selecionam o público que vai visualizar o perfil conforme as preferências cadastradas. Pode-se afirmar que o Tinder é uma espécie "Linkedin ${ }^{4}$ do amor". As pessoas curtem o perfil daqueles candidatos que mais lhe interessam, ou seja, quanto mais curtidas mais qualificado se tornaria o usuário para uma possível interação ou futura relação, uma corrida da meritocracia do afeto. $\mathrm{O}$ "match" ocorre quando existe um interesse mútuo. E aí a interação salta para um nível mais elevado que é o de troca de mensagens ou pode avançar diretamente para um encontro.

Em conversa empírica com usuários do Tinder, detecta-se que as trocas de mensagens se configuram como uma entrevista. Códigos de comunicação diferenciados por geração, pela interpretação de memes $^{5}$ de rede são examinados num processo de verificação de compatibilidade e, ao mesmo tempo, análise de riscos. Segundo estes usuários não é tolerada a possibilidade de frustração. A qualquer sinal de incompatibilidade ou de futura rejeição o "candidato" é eliminado da corrida.

\section{Algumas conclusões}

As redes sociais mediadas tecnologicamente alteraram a percepção que tínhamos sobre as capacidades de nossas relações, ao possibilitarem a queda de barreiras de espaço e tempo, ampliando potencialmente a frequência de contato. Estas redes podem ter sido, em alguns casos, catalizadoras de relações afetivas bem sucedidas, bem como de muitos fracassos.

Comparando os primeiros formatos de redes sociais como o Orkut com o Facebook, por exemplo, verifica-se que a aceleração da velocidade das informações circulantes nas linhas de tempos das redes contemporâneas teria aumentado o número de interações. $\mathrm{O}$ que podemos perguntar é se esse aumento teria causado um inchaço no volume interacional e não um aumento de densidade na qualidade destas interações.

\footnotetext{
${ }^{4}$ Linkdin - Rede baseada em troca de experiências profissionais.

${ }^{5}$ Meme é um termo cunhado por Richard Dawkins em seu livro "O Gene Egoísta" (1991) no qual é definido como uma entidade, um "gene da cultura", partículas de sentidos que seriam reproduzidos por seus replicadores que seriam as pessoas, como coloca Recuero (2009). Os memes da internet podem ser desde frases e expressões, como também imagens articuladas com frases ou mesmo vídeos que se viralizam pela redes sociais.
} 
O Tinder, conhecida rede de relacionamentos íntimos virtuais que apresenta uma ambiente que oferece aos seus usuários aparentes garantias de se resguardar que a pessoa que ele busca se relacionar teria um mínimo de características que ele precisaria para que a relação seja bem sucedida em sua intenção.

Bauman (2004) define que a era dos Amores Líquidos é um período do qual os indivíduos se colocam amedrontados em encarar os riscos de uma relação amorosa profunda e duradoura, com todos os custos do aprendizado do outro, a luta nos processos de transformação para manter os laços fortes e frequentes. Talvez seja mais cômoda a vivência dos choques das emoções das relações mediadas por aplicativos de relacionamento que assegurariam a fruição do prazer em detrimento da dor da construção de uma relação.

O filme "Contato" (1997) encerra a experiência de interação com a inteligência alienígena como se fosse uma experiência de transcendência religiosa, ao mesmo tempo também científica, pois a cientista teria vivenciado uma viagem interdimensional. Contudo, esta viagem não pôde ser comprovada pelos cientistas que acompanhavam a experiência, uma vez aos olhos deles a espaçonave que ela embarcara apenas caiu no mar. A experiência presentificada pertencia apenas à ela que vivenciou o fenômeno, como se fosse um presente exclusivo para aquela pessoa que já teria em seu repertório de vivência a condição de extrair daquela experiência algum aprendizado para si.

Talvez o amor não caiba cognitivamente em um mundo que precise transmitir publicamente todas as suas experiências. $\mathrm{O}$ amor seria uma vivência particular entre os agentes da relação. Bauman (2004) ao refletir sobre a afinidade a coloca como um construto daqueles que têm coragem de se arriscar no exercício da relação do convívio presencial com todos os riscos e benefícios que ele possa trazer.

Até o momento, as tecnologias de interação ainda não substituíram completamente a experiência do encontro face a face em sua riqueza e complexidade, e talvez isso nunca venha a acontecer com total fidelidade. Contudo, a singularização das experiências produzidas nas frequências das curtidas, das postagens de imagens e outras formas de interações, gerariam no usuário uma sensação de sonho lúcido vivido intensamente na construção de "laços fortes" virtuais, na montagem de uma narrativa amorosa digital. Amor ou ficção? No mínimo, uma experiência que pode ser também prazerosa ou compensadora ao ego, pelo menos enquanto o ato de trocas afetivas materializadas nas linhas de tempo das redes perdurarem. 


\section{Referências}

AGAMBEN, Giorgio. O que é dispositivo In: O que é o contemporâneo e outros ensaios. Chapecó: Argos, 2009. p.28-50.

ALMEIDA, Maria Isabel Mendes de; TRACY, Kátia Maria de Almeida. Noites Nômades: espaço e subjetividade nas culturas jovens contemporâneas. RJ: Rocco, 2003.

BAUMAN, Zygmunt. Amor Liquido: Sobre a Fragilidade dos Laços Humanos. ed. 1. Rio de Janeiro: Zahar, 2004. 190 pg.

CONTATO. Direção: Robert Zemeckis. Warner Home Video ,1997. 1 DVD (150 min), NTSC, Color.

CONTATOS Imediatos do Terceiro Grau. Direção: Steven Spielberg . 1977. 1 DVD ( 137 min.), NTSC, Color.

MISTÉRIOS DO MUNDO. Entendendo a Teoria da Relatividade de Einstein. Disponível em <http://misteriosdomundo.org/entendendo-a-teoria-da-relatividade-de-einstein/>. Acesso em 4 de junho de 2016.

PINTO, Julio C. M. Logos Sensorial. Contemporanea, vol. 8, n² 2. Dez.2010. Disponível em $<$ http://www.portalseer.ufba.br/index.php/contemporaneaposcom/article/viewFile/4859/3600

$>$ Consultado em 18 de maio de 2016

RECUERO, Raquel. Redes sociais na internet. Porto Alegre: Sulina, 2009. (Coleção Cibercultura) $191 \mathrm{p}$.

REVISTA ÉPOCA\& NEGÓCIOS. Linha do Tempo: do Facebook ao IPO. Disponível em $<$ https://www.tecmundo.com.br/rede-social/3667-a-historia-do-twitter.htm>. Consultado em 4 de junho de 2016.

SIBILIA, Paula. Os diários íntimos na Internet e a crise da interioridade psicológica. Disponível em <http://antroposmoderno.com/antro-version-imprimir.php?id_articulo=1143 $>$. Visualizado em 18 de maio de 2016.

TECMUNDO. A história do Twitter. Disponível em <https://www.tecmundo.com.br/redesocial/3667-a-historia-do-twitter.htm>. Consultado em 04 de junho de 2016.

TECHTUDO. Tinder ganha nova interface e mais recursos, como o envio de GIFs. Disponível em <http://www.techenet.com/2016/01/tinder-ganha-nova-interface-e-maisrecursos-como-o-envio-de-gifs/> . Acesso em 02 de junho de 2016. 